\title{
An Analysis of Spatio-Temporal Trends of Land Surface Temperature in the Dhaka Metropolitan Area by Applying Landsat Images
}

\author{
Musammat Shahinara Begum ${ }^{1,2^{*}}$ (1) , Sujit Kumar Bala1, AKM Saiful Islam ${ }^{1}$ (D), \\ GM Tarekul Islam1, Debjit Roy ${ }^{3}$ (i)
}

\begin{abstract}
${ }^{1}$ Institute of Water and Flood Management (IWFM), Bangladesh University of Engineering and Technology (BUET), Dhaka, Bangladesh ${ }^{2}$ Survey and Investigation Division, Irrigation Wing, Bangladesh Agricultural Development Corporation (BADC), Dhaka, Bangladesh ${ }^{3}$ Irrigation and Water Management Division, Bangladesh Rice Research Institute (BRRI), Gazipur, Bangladesh Email: ^shahinara.ace@badc.gov.bd
\end{abstract}

How to cite this paper: Begum, M.S., Bala, S.K., Islam, A.K.M.S., Islam, G.M.T. and Roy, D. (2021) An Analysis of Spatio-Temporal Trends of Land Surface Temperature in the Dhaka Metropolitan Area by Applying Landsat Images. Journal of Geographic Information System, 13, 538-560.

https://doi.org/10.4236/jgis.2021.134030

Received: July 19, 2021

Accepted: August 16, 2021

Published: August 19, 2021

Copyright $\odot 2021$ by author(s) and Scientific Research Publishing Inc. This work is licensed under the Creative Commons Attribution International License (CC BY 4.0).

http://creativecommons.org/licenses/by/4.0/

(c) (i) Open Access

\begin{abstract}
Land surface temperature (LST) is a basic determinant of the global thermal behavior of the Earth surface. LST is a vital consideration for the appraisal of gradual thermal change for urban areas to examine the strength of the thermal intensity of the surface of urban heat island (SUHI) and to see how hot the surface of the Earth would be in a particular location. In this respect, the most developed urban city like Dhaka Metropolitan Area (DMA), Bangladesh is considered for estimation of LST, and Normalized Difference Vegetation Index (NDVI) changes trend in more developed and growing developing areas. The focus of this study is to find out the critical hotspot zones for further instantaneous analysis between these two types of areas. The trends of long-term spatial and temporal LST and NDVI are estimated applying Landsat images-Landsat 5-TM and Landsat OLI_TIRS-8 for the period of 1988 to 2018 for DMA and for developed and growing developing areas during the summer season like for the month of March. The supervised classification was used to estimate the land cover categories and to generate the LST trends maps of the different percentiles of LSTs over time using the emissivity and effective at sensor brightness temperature. The study found the change in land cover patterns by different LST groups based on 50th, 75th, and 90th percentile where the maximum LST for the whole DMA went up by $2.48^{\circ} \mathrm{C}$, $1.01^{\circ} \mathrm{C}$, and $3.76^{\circ} \mathrm{C}$ for the months of March, April, and May, respectively for the period of 1988 to 2018 . The highest difference in LST was found for the most recently developed area. The moderate change of LST increased in the built-up areas where LST was found more sensitive to climate change than the growing developed areas. The vegetation coverage area decreased by $6.74 \%$ in the growing, developing areas compared to the developed areas
\end{abstract}


from 1988 to 2018. The findings of the study might be helpful for urban planners and researchers to take up appropriate measures to mitigate the thermal effect on urban environment.

\section{Keywords}

Land Surface Temperature, Surface Urban Heat Island, Urban Thermal Environment, NDVI Change, Vegetation Coverage Change

\section{Introduction}

The rapid urbanization process plays a key role within the formation of urban heat islands (UHI), where the heating would have a further impact upon the urban life quality [1] [2] [3]. A UHI phenomenon creates in urban city areas with substantially warmer temperatures than adjacent rural areas causing huge thermal discomfort to all living entities within the city [4]. Natural landscapes of rural areas are transformed into modern land use and land covers like buildings, markets, roads, and other impervious surfaces, making urban landscapes fragmented and sophisticated and raising the urban temperature affecting the lives of urban dwellers. Urban land cover changes (ULCC) are mainly caused by the removal of natural vegetation cover, mainly responsible for the microclimate change of the town [5]. In general, the surface cover with vegetation and water provides lower surface temperature. In 1990, only $15 \%$ of the world's population lived in cities, while within the 20th century, this picture has been completely changed with about $50 \%$ population of the planet is estimated to reside in cities [6]. LST may be a controlling factor for many of the physical, chemical, and biological processes in the world and may be considered as a measuring indicator of global climate change [7]. For the urban environment, LST may be a crucial parameter for monitoring of the energy exchange between the land surface and thus the atmosphere in terms of the sensible and heat transformation fluxes [8]. This bears importance when discussing about the thermal effects of the cities on the regional climate. An understanding of LST is vital for urban climatology, global environmental change, and human-environmental interactions [9]. In fact, the observed geographical and ecological patterns and processes tend to be spatial variables. Therefore, the relationships between LST and its impact factors are often characterized by local changes [10]. It has been found that the relationship between land use land cover (LULC) type and LST is very strong with a strong positive correlation $\left(\mathrm{r}^{2}=0.9281\right)$ [11] [12] [13].

The DMA in Bangladesh is undergoing rapid urbanization transforming into a hotter city. The LST in Dhaka City has been increased substantially within the city area [4] [14] [15]. Most of the prevailing research has been accomplished based upon the LST changes or land cover (LC) changes in DMA [16] [17] [18] [19] [20] for the period of 1989-2009. The LSTs were retrieved to know the variation of temperature from rural areas to urban areas [21]-[26]. Another study 
found that agricultural land had been decreased from $67.38 \%$ to $62.20 \%$ between 1976 and 2014 having an annual rate of $0.56 \%$ between 2001 and 2008. The increase of the urban areas was found from $11 \%$ to $34.4 \%$ between 1960 and 2005 in Dhaka city. It has also been found that the warming has been mostly connected to Dhaka city due to urbanization having a global phenomenon [27].

However, no studies were found on the trend of the variation of LST and LC changes in the developed and growing developing areas of DMA, Bangladesh during the summer season. With this respect, the study was aimed to provide a comprehensive assessment of the thermal environment using remote sensing data over time in the selected locations of DMA. The objectives were: 1) to determine trends in the frequency of extreme temperature indices; 2) to analyze the spatial patterns of extreme temperature related indices; and 3) to assess the statistical significance of the trends in indices of extreme temperature through parametric and non-parametric tests. The knowledge generated by this study will be an aid to assess and mitigate the socio-economic impacts of the increased thermal changes in the UHI of the DMA.

\section{Materials and Methods}

\subsection{Study Area and Datasets}

Dhaka City as Dhaka Metropolitan Area (DMA) is located almost in the geographical center of Bangladesh at $23^{\circ} 43^{\prime} 0^{\prime \prime} \mathrm{N}$ and $90^{\circ} 24^{\prime} 0^{\prime \prime E}$ (Figure 1). Dhaka city is the capital of Bangladesh. It is rapidly growing in terms of population and extent. In 2016, the population of the greater Dhaka area was 18.237 million. The city has been transformed into a mega city of about 19.56 million people. Now it is the hub of the industrial, commercial, cultural, educational, and political activities of the country [28] [29]. The city is rich with colorful history and cultural tradition. Dhaka is famous for her big numbers of mosques and ancient muslin already revived very recently. This profile captures the unplanned and spontaneous urbanization of Dhaka, which has been resulted in unplanned and disorganized spatial expansion and transformation of the city. The unbalanced urban primacy is the result of a high concentration of administrative activities, jobs, and services in the city [30]. Such a dramatic urbanization process inevitably has brought an UHI effect on the entire city due to the increasing built-up density and the loss of urban green spaces. For the research purposes, study areas were categorized into two types: developed and growing developing areas. For this study, we selected Motijheel, Gulshan, and Uttara as developed area and Demra, Pallabi for growing developing areas within the DMA.

The developed area was considered based on land use, and land cover categories of the specific areas, like Motijheel was considered as developed area, and Pallabi was considered as growing developing areas. Conversely, Motijheel represented the prime commercial area of the Dhaka district. Head offices of a variety of commercial establishments exist in Motijheel. On the other hand, Pallabi Thana is bounded by natural almost geographical settings. Uttara thanas are 


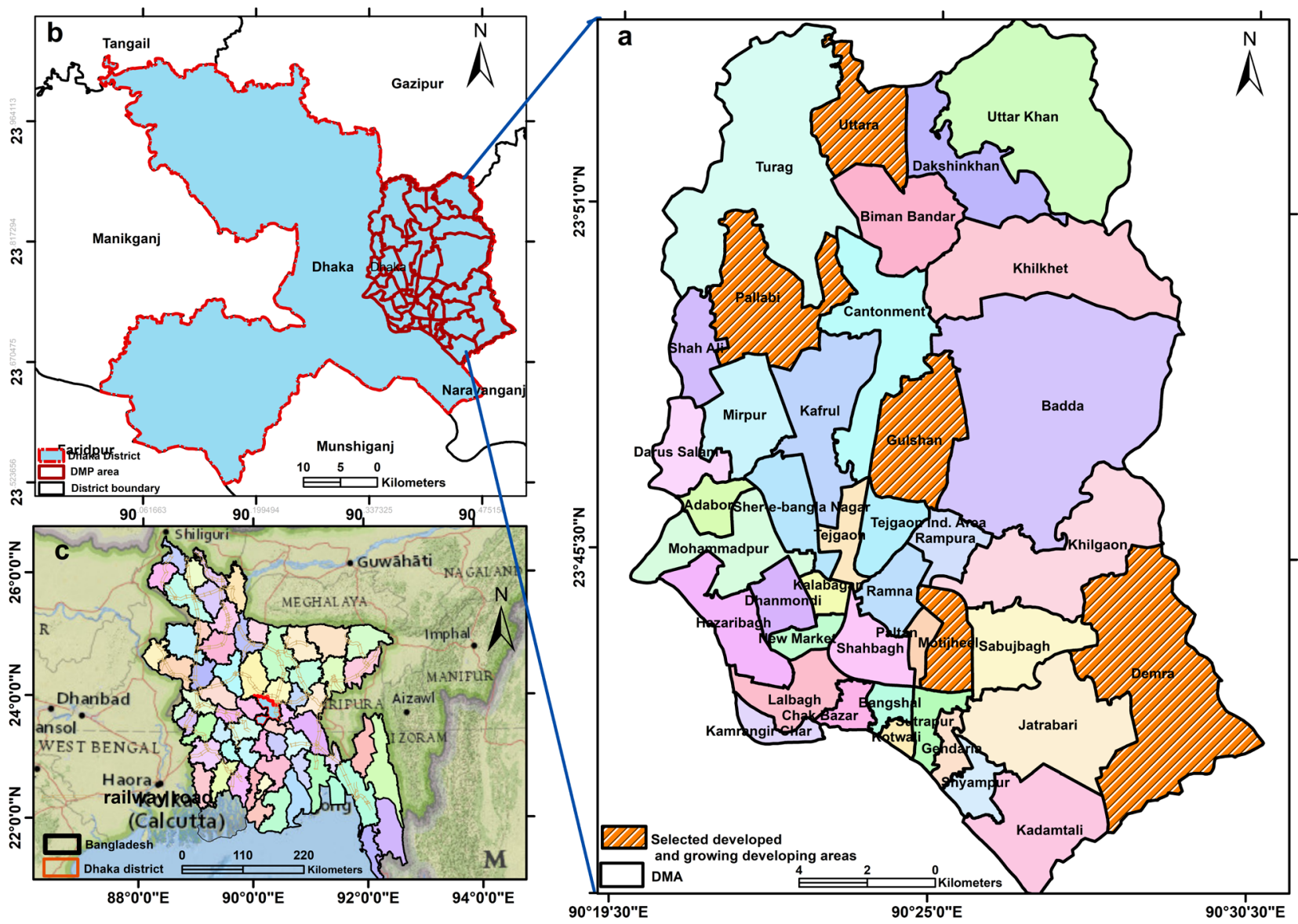

Figure 1. (a) Study area (Dhaka metropolitan area with developed and growing developing area); (b) Dhaka district; (c) Bangladesh with base map.

on the north, Mirpur model and Shah Ali thanas are on the south, Biman Bandar, cantonment and Kafrule thanas are on the east and Savar Upazila is on the west. Pallabi is a growing area with residential facilities like markets and shopping centers mostly in a planned way. A large portion of land is yet to come under developmental activities. So, Pallabi was considered as a growing and developing area [31].

The time series of Landsat images taken by the Landsat TM and Landsat Operational Land Imager (OLI)/Thermal Infrared Sensor (TIRS) were obtained from the USGS website. Landsat images were available from 1988 to 2018, as shown in Table 1. The Landsat TM passed over the study area between approximately 3:45 and 3:50 GMT and Landsat OLI/TIRS passed over the study area between approximately 4:10 and 4:30 GMT. This provided a good opportunity for collecting images with maximum illumination, especially for LST studies. Satellite images were clustered by a 10-year period as 1988-1997, 1998-2007, and 2008-2018. The trends of percentile groups of LST were found for the selected months from each group with an average value of LST of different percentiles. Similarly, trend of vegetation coverage was found for the same period and same group from each group with an average value of normalized difference 
Table 1. Information about Landsat images used in the study.

\begin{tabular}{lcclcc}
\hline Year Range & Sensor Type & $\begin{array}{c}\text { Number } \\
\text { of Images }\end{array}$ & Acquisition Months & Path/rows & $\begin{array}{c}\text { Spatial } \\
\text { Resolution }\end{array}$ \\
\hline $1988-1997$ & TM & 106 & March, April \& May & $137 / 44$ & $30 \mathrm{~m}$ \\
$1998-2007$ & TM & 90 & March, April \& May & $137 / 44$ & $30 \mathrm{~m}$ \\
$2008-2018$ & TM and OLI/TIRS & 117 & March, April \& May & $137 / 43$ and 137/44 & $30 \mathrm{~m}$ \\
\hline
\end{tabular}

vegetation index (NDVI). Google Earth Engine and ArcGIS version 10.6 were used for image processing. Microsoft Excel was used for conducting the statistical analysis using the multi-buffering method. Pre-processing was done for the Landsat images to remove the biases [32]. Usually, it was not necessary to conduct a geometric correction for Landsat level 1 products, as they were registered through a systematic process [33]. The main correction was radiometric and eliminates errors that affect the brightness values of the pixels [34]. These errors were mainly due to detection errors in the sensor system and environmental attenuation errors. The original image sizes were larger than the study area, so after pre-processing, they were edited using a shapefile of the DMA. In Table 1, the Landsat images used in the study are shown.

\subsection{Image Pre-Processing}

Landsat 5 TM and Landsat 8 OLI/TIRS were acquired for the summer months like March, April, and May from 1988 to 2018 for deriving LST trends. The images received from the USGS website (https://earthexplorer.usgs.gov/) and cloud-free images or images with minimal cloudiness (less than 5\%) were considered. All bands of the satellite imagery of the DMA (band $2-8$ and $10-11$ ) were clipped to the study area boundary. Before land cover (LU) classification mapping and LST trend, these satellite images were subjected to a group of preprocessing procedures. The pre-processing included radiometric calibration and atmospheric correction (dark-object subtraction). Then, the pictures were further resampled with pixel sizes of $30 \mathrm{~m}$ by $30 \mathrm{~m}$ for all bands, including the thermal band. The ultimate urban landscape was divided into different group classifications. During this process, with the Google Earth Engine, images with high spatial resolution and other auxiliary data were calculated to spot the land use types. Overall, the entire accuracy of the land use classification was achieved over $86.6 \%$ [35]. Alongside the LST data, Landsat image of the clear sky days were used for the accurate estimation of the LST averages for the month of March, April, and May. To make sure the reliability of the monthly LST values, a minimum threshold of twelve clear sky days per month was set. Additionally, the standard assurance data sets were used, and only good data quality pixels were selected, which have a mean error for emissivity $\leq 0.01$ and for LST $\leq 1 \mathrm{~K}$ [36].

\subsection{Estimation of Land Surface Temperature}

The land surface temperature (LST) was derived from atmospherically corrected 
Landsat 5 TM (band 6) and from Landsat 8 TIRS (band 10) through the raster calculation in ArcGIS. In this study, the supervised classification was used to estimate the land cover categories and to generate the LST trends maps of the different percentiles of LSTs over time using the emissivity and effective at-sensor brightness temperature. All equations were considered from USGS website. The additional input parameters such as atmospheric water vapor content and near surface air temperature from ground-based observations were also required to calculate the LST. They were usually unavailable [37]. All the digital numbers (DN values) of thermal bands were converted into spectral radiance using Google Earth Engine. A three-step process was followed to derive the LST from Landsat image in both developed and growing developed areas [38]. The trend of different percentile of LST over time like $50^{\text {th }}, 75^{\text {th }}$, and $90^{\text {th }}$ percentile for the whole DMAs was estimated by different year LST groups. The thermal infrared observations are easily contaminated by cloudiness, leading to many gaps during the LST estimation [39]. So, it is indispensable to observe the LST trend in the different locations of urban areas for further adaptation of the microclimatic changes or to mitigate the UHI. To mitigate global warming, LST is a very cohesive factor that increases UHI. The final step of retrieving the LST or the emissivity-corrected land surface temperature was computed using the emissivity and effective at-sensor brightness temperature, where images were further used to derive LST using Equation (1) [11] [30]:

$$
\mathrm{LST}=\frac{\mathrm{BT}}{\left(1+\left(\frac{\lambda \mathrm{BT}}{\rho}\right) * \ln n(\varepsilon)\right)}
$$

where $\mathrm{LST}$ is in ${ }^{\circ} \mathrm{C}, \mathrm{BT}$ is the at sensor brightness temperature $\left({ }^{\circ} \mathrm{C}\right), \lambda$ is the average wavelength of the specific band, $\varepsilon$ is the emissivity and $\rho=h c / \sigma, \sigma=$ Boltzmann constant $\left(1.38 \times 10^{-23} \mathrm{~J} / \mathrm{K}\right), h$ is Planck's constant $\left(6.626 \times 10^{-34} \mathrm{~J} / \mathrm{s}\right), c$ is the velocity of light $\left(2.998 \times 10^{8} \mathrm{~m} / \mathrm{s}\right)$.

\subsubsection{Calculation of Brightness Temperature}

The Equation for calculating the brightness temperature Equation (2) is that the same for Landsat TM, ETM+ and OLI/TIRS [40]:

$$
\mathrm{BT}=\frac{K_{2}}{\ln \left(\frac{K_{1}}{L}+1\right)}-273.15
$$

where $\mathrm{BT}$ is the effective satellite temperature (brightness temperature) in ${ }^{\circ} \mathrm{C}, K_{1}$ is that the band-specific conversion constant, and $K_{2}$ is another calibration constant in Kelvin. Therefore, values of $K_{1}$ and $K_{2}$ are constant for OLI/TIRS, but the values of bias and gain values could also be different for various satellite images.

\subsubsection{Calculation of Top of Atmospheric (TOA) Spectral Radiance}

Pixel values represent the digital number (DN). Radiance depends on the illumination (both its intensity and direction) and on the orientation and position 
of the target. The top-of-atmosphere (TOA) earth radiation budget (ERB) may be a key property of the climate system that describes the balance between what proportion of solar power the world absorbs and the way much terrestrial thermal infrared it emits. The DN values were converted to TOA Spectral radiance and calculated using the subsequent Equation (3) [41]:

$$
\operatorname{TOA}(L)=M_{L} * Q_{\text {cal }}+A_{L}
$$

Here, $M_{L}$ represents the band-specific multiplicative rescaling factor from the metadata, $Q_{\text {cal }}$ is the Quantized and calibrated standard product pixel values, correspond to band 10, $A_{L}$ is the band-specific additive rescaling factor from the metadata, the pixel values of satellite images (DN) were converted to Kelvin and further to Celsius.

\subsubsection{Estimation of Emissivity}

Surface emissivity is important for calculation of land surface temperature by remote sensing. There have been several studies on emissivity. Among these, we adopted the frequently used method of the estimation of emissivity using simplified normalized difference vegetation index (NDVI) thresholds derived from the spectral reflectance in the red and near-infrared bands. It is assumed that the surface is flat and homogeneous. The conditional Equation (4) for estimation of emissivity [42] is as follows:

$$
\text { Emissivity }=\varepsilon v \lambda P v+\varepsilon s \lambda(1-P v)+C \lambda
$$

where $\mathcal{E} V$ and $\varepsilon s$ are the vegetation and soil emissivity.

In this study, values of vegetation and soil emissivity 0.98 and 0.92 , respectively; $C$ represents the surface roughness taken as a constant value of 0.005 ( $C=$ 0 for flat surfaces and homogenous), $\lambda$ represents wavelength $(\mu \mathrm{m}), P_{V}$ is the fraction of vegetation or proportion of vegetation $\left(P_{V}\right)$ is calculated by the following Equation (5).

$$
P v=\left(\frac{\mathrm{NDVI}^{-} \mathrm{NDVI}_{\text {min }}}{\mathrm{NDVI}_{\text {max }}-\mathrm{NDVI}_{\text {min }}}\right)^{2}
$$

\subsubsection{Estimation of Normalized Difference Vegetation Index (NDVI)}

In this study, NDVI was used to express the vegetation land cover changes in urban area specifically, in the more developed and growing developing areas within the study area and differences in the spatial resolution of the images, which are within $30 \mathrm{~m}$. GIS tools were then applied to the data using visual analysis, reference data, as well as local knowledge to split and recode these covers. It was done to closely reflect their true classes. Conversely, assessment of NDVI for a specified pixel always results in a number that ranges from -1 to +1 . The Normalized Difference Vegetation Index (NDVI) was calculated by the equation (6). Three main types were identified: low vegetation, medium vegetation, and high vegetation. In this study, NDVI values were selected less than 0 to 0.05 for low vegetation, 0.05 to 0.2 for medium vegetation, and 0.2 to 1 for high vegetation. The satellite data from 1988 to 2018 were studied using spectral and 
spatial profiles to ascertain the digital numbers (DNs) of different categories prior to classification. The supervised classification of NDVI was reclassed because sometimes urban landfill were merged with other classes, which were not possible to separate them due to their similar spectral properties. So, reclassification was used to improve the accuracy of the classification by the physical field survey method. In this study, classification accuracy referred to communication between the remotely sensed data and reference physical information of those pixel values. In order to assess the accuracy of land cover maps extracted from Landsat data, a total of 20 stratified random pixels were generated for the year 2018.

$$
\mathrm{NDVI}=\frac{(\mathrm{NIR}-\mathrm{Red})}{(\mathrm{NIR}+\mathrm{Red})}
$$

NDVI is calculated for Landsat 5 TM and Landsat 8 OLI \& TIRS with the following prescription:

NDVI for Landsat 8 OLI \& TIRS $=($ Band $5-$ Band 4$) /($ Band $5+$ Band 4$)$ and NDVI for Landsat 5 TM, NDVI $=($ Band $4-$ Band 3$) /($ Band $4+$ Band 3$)$.

NDVI will be computed temporally to understand the change of land cover during the study period and for the proportion of vegetation $\left(P_{V}\right)$. That is why $P_{V}$ is highly related to the NDVI and emissivity $(\varepsilon)$.

\subsection{Impact of Land Surface Temperature on Urbanization}

The mean LST values for the selected area, each class in the time scale were determined. The values of the LST within each selected area and the entire DMA zonal statistics in ArcGIS were used. Identification of the temporal dynamics of LST with urban land cover classes was the main intention in this step. Since the main consideration of this study was the analysis of the spatial and temporal trends of LST values, urban density and NDVI values in the urban land cover class were further extracted. LST values were reclassified according to $50^{\text {th }}, 75^{\text {th }}$, and $90^{\text {th }}$ percentiles for each month to analyze the trends of LST.

\section{Results and Discussion}

\subsection{Spatial Trends of Different Percentile of Land Surface Temperature (LST) and Vegetation and Land Cover Classification}

The LSTs of the study area were calculated from the Landsat images as discussed in the methodology. The common cloud cover for the selected months (MarchMay) for some places was considered as blank. As a result, some values did not maintain the regular trend of LST. The maximum, minimum, and other statistical values of LST could be calculated using the Zonal statistics in ArcGIS [43]. On the other hand, the land cover with vegetation was grouped considering the NDVI values. The classification results were mostly reliable, though overestimation of urban land cover with vegetation happened. Considering more accuracy, remotely sensed data were referenced in the practical information of 120 ran- 
dom pixels values of 2018. On the other hand, the maximum satellite image of March was cloud-free. That was why the month of March was considered for dry month, which was graphically represented by Figure 2 . This phenomenon could be best explained by the fact that vegetation could decrease the amount of heat stored in the soil or land surface through the process of transpiration [44].

The LST and NDVI maps of DMA in Figures 2(a)-(f) and developed and growing developing areas in Figures 3(a)-(f) were derived for the year group 1988-1997, 1998-2007, and 2008-2018. The average LST of the group of 2008-2018 was all along higher than the group of 1988-1997 and 1998-2007 (Figures 2(a)-(c). It was observed that, in the year group of 1988-1997, 1998-2007, and 2008-2018, LST values (min and max) in March in DMA showed ranges between $19.86^{\circ} \mathrm{C}$ to $28.11^{\circ} \mathrm{C}, 22.14^{\circ} \mathrm{C}$ to $31.19^{\circ} \mathrm{C}$, and $24.49^{\circ} \mathrm{C}$ to $31.95^{\circ} \mathrm{C}$, respectively. LST values in April in DMA showed ranges between $23.50^{\circ} \mathrm{C}$ to $29.58^{\circ} \mathrm{C}, 23.04^{\circ} \mathrm{C}$ to $29.80^{\circ} \mathrm{C}$, and $24.64^{\circ} \mathrm{C}$ to $30.59^{\circ} \mathrm{C}$ respectively. LST values in May in DMA showed ranges between $22.02^{\circ} \mathrm{C}$ to $26.66^{\circ} \mathrm{C}, 19.96^{\circ} \mathrm{C}$ to $29.94^{\circ} \mathrm{C}$, and $23.05^{\circ} \mathrm{C}$ to $30.42^{\circ} \mathrm{C}$, respectively. Similarly, it was observed that the average NDVI value for the year group 1988-1997, 1998-2007, and 2008-2018 was -0.239 to $0.501,-0.256$ to 0.458 , and -0.239 to 0.501 , respectively. This study also observed that the highest
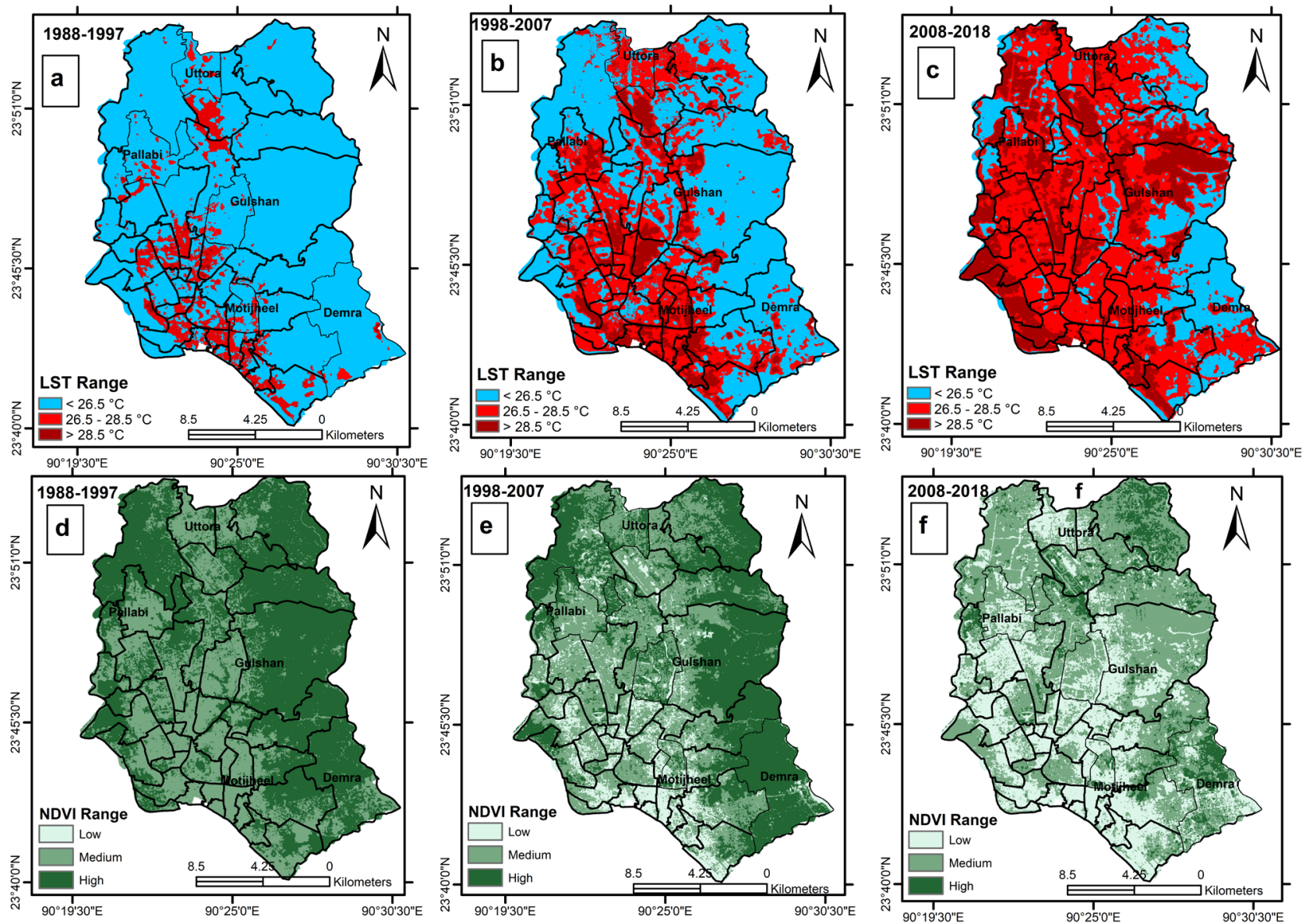

Figure 2. Land surface temperature (LST) trend maps (a, b, c) and normalize difference of vegetation index (NDVI) trend maps (d, e, f) for the month of March in the Dhaka metropolitan area (DMA) from 1988-2018. 

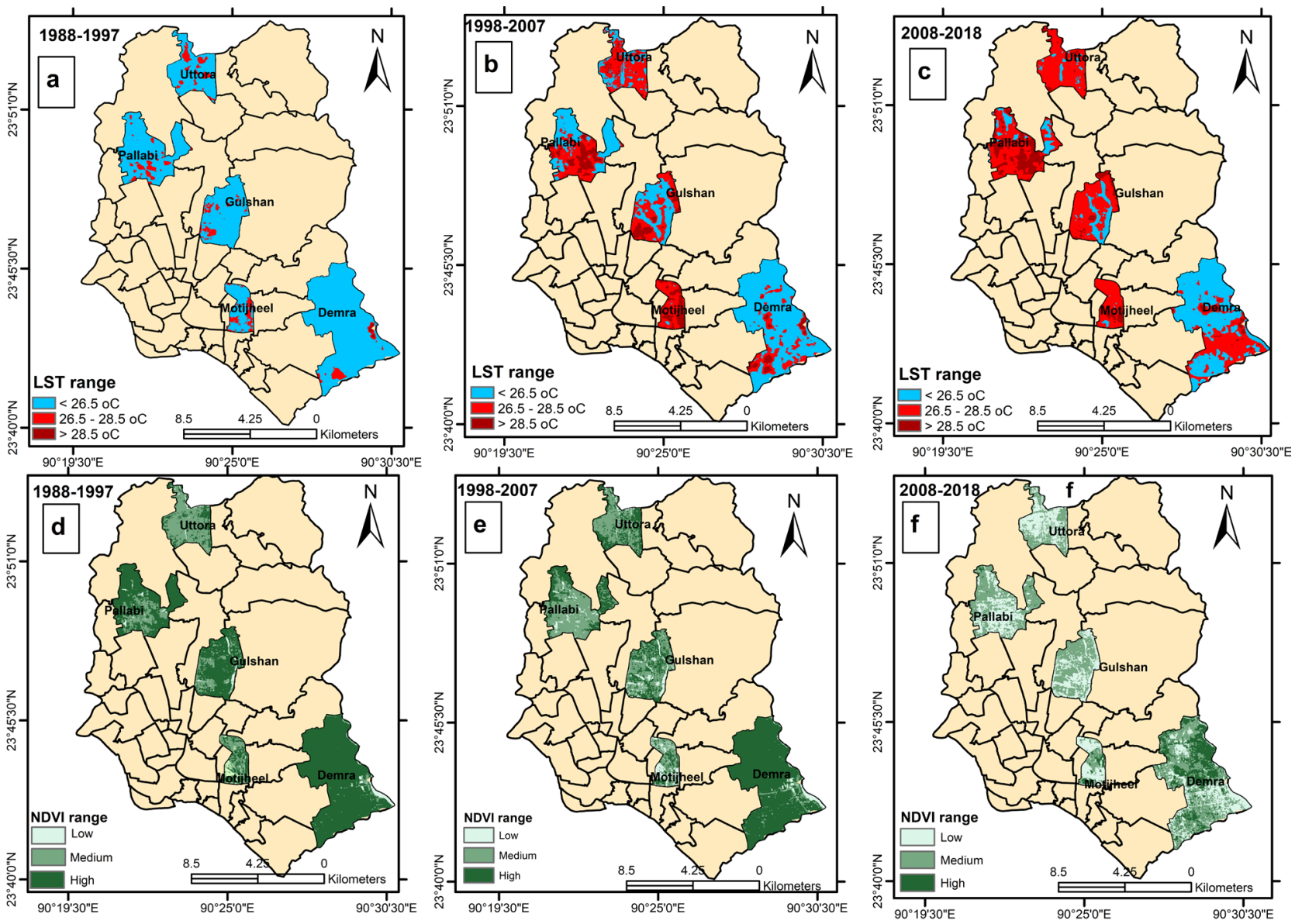

Figure 3. Land surface temperature (LST) trend maps (a, b, c) and normalize difference of vegetation index (NDVI) trend maps (d, e, f) for developed (Motijheel, Gulshan, Uttara) and growing developing area (Pallabi and Demra) from 1988-2018.

vegetation category for 1988 to 1997 was found $74 \%$ to $95 \%$ of the total land area, medium range of vegetation was $2.44 \%$ to $25.49 \%$ of the total area, while low vegetation category was $1.47 \%$ to $3.26 \%$ of the total area. On other hand, in 2014, the highest low vegetation category was found in the developed areas of Motijheel, Uttara, and Gulshan by $68.51 \%, 76.55 \%$, and $56.60 \%$ respectively of total land area. Therefore, it was strongly established that vegetation coverage in the urban areas was decreasing being replaced by built up areas. For the last 30 years, it decreased by $28.88 \%$ - $95 \%$ of the total area. This trend was true mainly for built up areas. It was increasing for both growing developing and developed areas for the more populated city. So, LST had a strong positive relation to the vegetation index and highest vegetation category which was found in the lower range of LST in Figures 2(d)-(f).

Moreover, this study also graphically analyzed the LST trend in the developed and growing developing areas. The trends of LSTs and NDVI for the more developed and growing developing areas such as Motijheel, Gulshan, Uttara and Demra, Pallabi for the month of March to May within the year group of 19881997, 1998-2007, 2008-2018 were analyzed. Figures 3(a)-(f) displayed the spatial distribution of the LST trend map and NDVI trend map for the month of March 
which was presented for the urban pixels of the developed area of Motijheel, Gulshan, Uttara and the growing, developing area of Pallabi and Demra of the selected year groups. The LST varied in the developed area from minimum $21.14^{\circ} \mathrm{C}$ to maximum $30.96^{\circ} \mathrm{C}$, from minimum $21.56^{\circ} \mathrm{C}$ to maximum $31.30^{\circ} \mathrm{C}$, and from minimum $21.70^{\circ} \mathrm{C}$ to maximum $32.12^{\circ} \mathrm{C}$ for the year groups of 1988-1997, 1998-2007, and 2008-2018, respectively in the month of May. Similarly, they were found from $22.90^{\circ} \mathrm{C}$ to $30.78^{\circ} \mathrm{C}$, from $23.02^{\circ} \mathrm{C}$ to $31.31^{\circ} \mathrm{C}$, and from $26.96^{\circ} \mathrm{C}$ to $30.44^{\circ} \mathrm{C}$ in April. In March, LST trend was found from $19.35^{\circ} \mathrm{C}$ to $38.50^{\circ} \mathrm{C}$, from $21.45^{\circ} \mathrm{C}$ to $31.34^{\circ} \mathrm{C}$ and from $23.51^{\circ} \mathrm{C}$ to $30.75^{\circ} \mathrm{C}$, respectively for those year groups. It was also detected that the maximum highest trend of LST was found $27.17^{\circ} \mathrm{C}$ to $30.39^{\circ} \mathrm{C}$, from $26.96^{\circ} \mathrm{C}$ to $30.14^{\circ} \mathrm{C}$, and from $24.94^{\circ} \mathrm{C}$ to $30.96^{\circ} \mathrm{C}$ for $1988,1998,2008$, and 2018 in May, respectively (Table 2). The maximum average temperature value of the developed area was found $37.93^{\circ} \mathrm{C}$ and the highest difference in the LST trend was found $2.97^{\circ} \mathrm{C}$ between the developed areas.

The trend of LST for the growing, developing areas for March was found by $16.82^{\circ} \mathrm{C}$ to $29.77^{\circ} \mathrm{C}, 18.0^{\circ} \mathrm{C}$ to $34.50^{\circ} \mathrm{C}$ and $25.15^{\circ} \mathrm{C}$ to $32.20^{\circ} \mathrm{C}$ while for April was found from $21.60^{\circ} \mathrm{C}$ to $32.80^{\circ} \mathrm{C}, 22.21^{\circ} \mathrm{C}$ to $35.31^{\circ} \mathrm{C}$ and $27.67^{\circ} \mathrm{C}$ to $32.54^{\circ} \mathrm{C}$

Table 2. The trend of minimum, maximum, and mean LST of the selected developed and growing developing area for the year group of 1988-1997, 1998-2007, and 2008-2018.

\begin{tabular}{|c|c|c|c|c|c|c|c|c|c|}
\hline \multirow{2}{*}{ Thana } & \multicolumn{3}{|c|}{ Year group 1988-1997 } & \multicolumn{3}{|c|}{ Year group 1998-2007 } & \multicolumn{3}{|c|}{ Year group 2008-2018 } \\
\hline & Min & $\operatorname{Max}$ & Mean & Min & $\operatorname{Max}$ & Mean & Min & $\operatorname{Max}$ & Mean \\
\hline \multicolumn{10}{|c|}{ MARCH } \\
\hline Gulshan & 21.99 & 28.18 & 23.77 & 21.45 & 30.80 & 26.13 & 23.51 & 30.75 & 27.13 \\
\hline Motijheel & 21.86 & 37.93 & 29.90 & 25.11 & 31.21 & 28.16 & 25.36 & 29.70 & 27.53 \\
\hline Uttara & 20.17 & 27.49 & 23.83 & 22.73 & 31.34 & 27.04 & 25.28 & 30.41 & 27.84 \\
\hline Pallabi & 21.11 & 28.51 & 22.67 & 18.95 & 31.35 & 25.15 & 24.22 & 31.43 & 27.82 \\
\hline Demra & 21.73 & 29.77 & 23.45 & 20.51 & 34.50 & 27.50 & 22.64 & 32.20 & 27.42 \\
\hline \multicolumn{10}{|c|}{ APRIL } \\
\hline Gulshan & 22.90 & 30.51 & 26.71 & 23.02 & 30.90 & 26.96 & 26.62 & 30.44 & 27.06 \\
\hline Motijheel & 24.90 & 30.09 & 27.50 & 25.02 & 31.31 & 28.17 & 28.03 & 30.04 & 27.70 \\
\hline Uttara & 23.66 & 30.57 & 27.12 & 24.30 & 29.66 & 26.98 & 26.75 & 30.41 & 27.85 \\
\hline Pallabi & 22.47 & 32.80 & 27.64 & 22.21 & 33.32 & 27.77 & 27.67 & 31.43 & 27.83 \\
\hline Demra & 21.60 & 32.71 & 27.16 & 22.59 & 35.31 & 28.95 & 27.98 & 32.54 & 27.64 \\
\hline \multicolumn{10}{|c|}{ MAY } \\
\hline Gulshan & 21.14 & 30.14 & 25.48 & 21.90 & 31.30 & 26.60 & 22.14 & 31.71 & 26.93 \\
\hline Motijheel & 23.12 & 30.39 & 26.29 & 23.40 & 31.10 & 27.25 & 23.52 & 31.30 & 27.41 \\
\hline Uttara & 21.43 & 30.96 & 25.74 & 21.56 & 30.96 & 26.26 & 21.70 & 30.98 & 26.34 \\
\hline Pallabi & 21.59 & 30.65 & 25.56 & 22.10 & 32.12 & 27.11 & 22.80 & 32.12 & 27.46 \\
\hline Demra & 21.50 & 30.10 & 25.46 & 22.20 & 32.20 & 27.20 & 22.42 & 32.92 & 27.67 \\
\hline
\end{tabular}


and for May they were found from $21.50^{\circ} \mathrm{C}$ to $30.65^{\circ} \mathrm{C}, 22.20^{\circ} \mathrm{C}$ to $32.20^{\circ} \mathrm{C}$ and $22.80^{\circ} \mathrm{C}$ to $32.92^{\circ} \mathrm{C}$ for $1988-1997,1998-2007$ and $2008-2018$ year groups, respectively. In the growing, developing areas such as Demra, Pallabi for the year group 2008-2018 LST was increased from 32.24\% - 43.97\% in March, from $5.30 \%-7.78 \%$ in April, and from $4.27 \%-5.59 \%$ in May compared to the year group of 1988-1997. For that reason, March was more sensitive to changing LST in the growing, developing areas. Conversely, in the developed areas, it was increased by $1.17 \%-16 \%$ in the year group of $2008-2018$ compared to the year group of 1988-1997 where March was also more sensitive month for LST change. Therefore, the change of the LST in an urban area was rapid, and the change of urban temperature over the last 30 years (during the period 1988 to 2018) had a positive trend and was very stronger in the more developed areas compare to less developed areas. This study revealed that the maximum LST trend for the whole area went up by $2.48^{\circ} \mathrm{C}, 1.01^{\circ} \mathrm{C}$, and $3.76^{\circ} \mathrm{C}$ in the months of March, April, and May from 1988 to 2018. Increases in the range values could be related to the time of images were captured, meaning that different times of the year affected the results during the same period. Particularly, the trends of the urban pixels during month of March were high, because of urban surface materials with higher radiant temperatures [42]. A large expansion of the built-up area was clearly reflected by an increased LST in the city center. LST in the developed areas was greater than growing developed areas by $2.97^{\circ} \mathrm{C}$. The study observed that the maximum LST change rate close to from $1.1^{\circ} \mathrm{C}$ to $3.76^{\circ} \mathrm{C}$ within the last 30 years in the urban areas.

\subsection{Spatial Trend of Area Coverage by Different Percentile of LST Groups and Different NDVI Ranges for the Developed and Growing Developing Areas}

The land area cover patterns by different temperature groups based on the $50^{\text {th }}$, $75^{\text {th }}$, and $90^{\text {th }}$ percentile showed a similar gradient to the temperature values in Figures 4(a)-(e). Furthermore, vegetation coverage mapping of the study area would provide information on the identification and estimation of trends of vegetation index changing over the past 30 years. The area changing scenarios of vegetation in these time frames for the months of March of the selected areas are also presented in Table 3. The land cover patterns with vegetation, which were identified by 3 categories used for the year 1988-2018, as well as land cover changes along the time, are listed in Table 3.

Along the time scale (1988-1997, 1998-2007, 2008-2018), in the month of March the percentage of areas covered by temperature ranges below $26.5^{\circ} \mathrm{C}$ was found by $88.51 \%, 58.43 \%, 25.31 \%$, respectively, for the range of $26.5^{\circ} \mathrm{C}$ to $28.5^{\circ} \mathrm{C}$ was found by $11.18 \%, 31.25 \%$, and $51.89 \%$, respectively and greater than $28.5^{\circ} \mathrm{C}$ was found by $31 \%, 10.32 \%$ and $22.80 \%$, respectively, which correspond to $50^{\text {th }}$, $75^{\text {th }}$ and $90^{\text {th }}$ percentiles, respectively. It was evident that in the months of March during 1988-1997, land area coverage by temperature range of $75^{\text {th }}$ percentile and $90^{\text {th }}$ percentile was related to rapidly increasing areas during the month of March 
and the area coverage with the temperature range $50^{\text {th }}$ percentile decreased by $71 \%$ where in $2008-2018$, it was going to $22.80 \%$. Similarly, area coverage for the

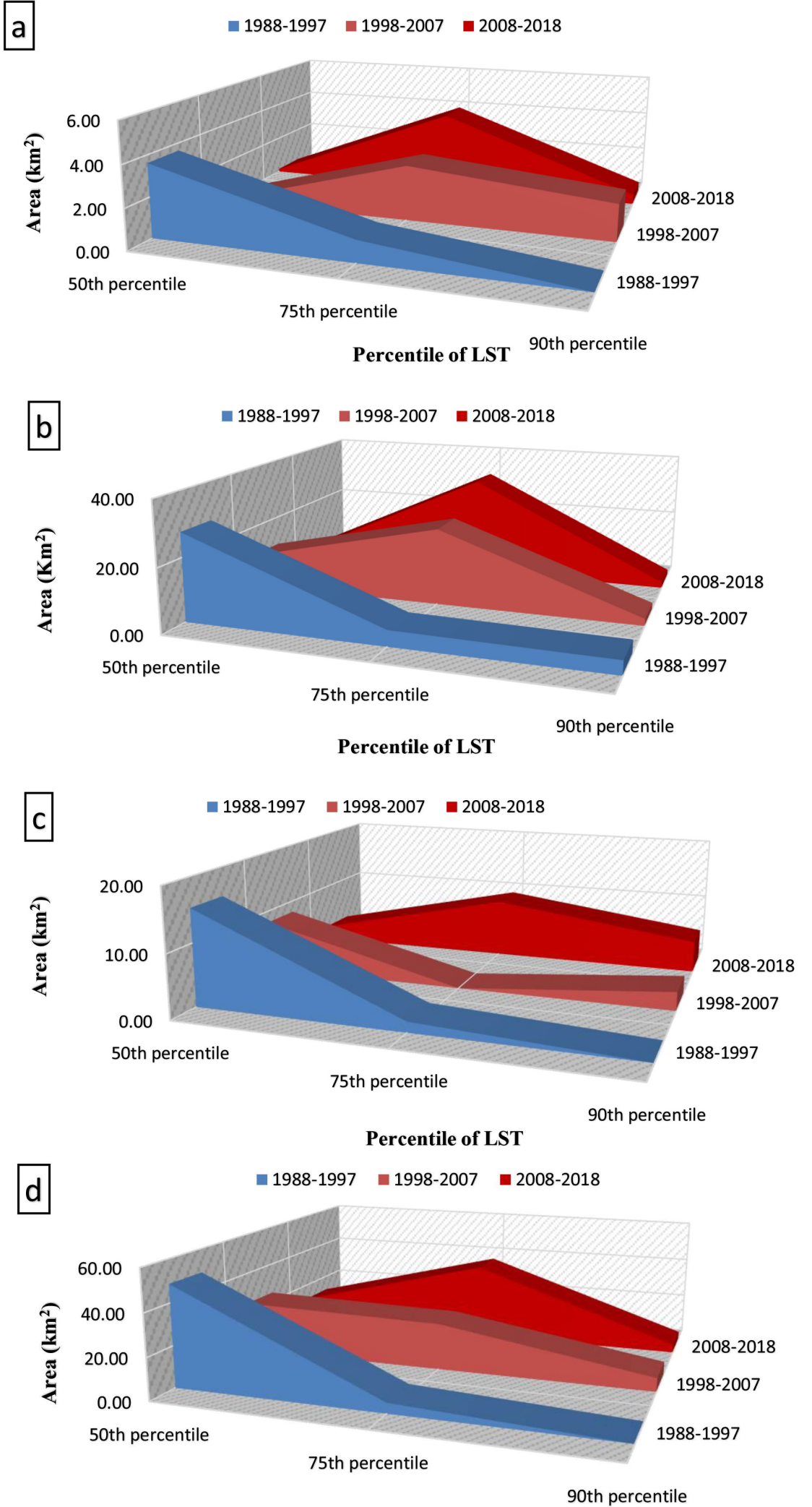




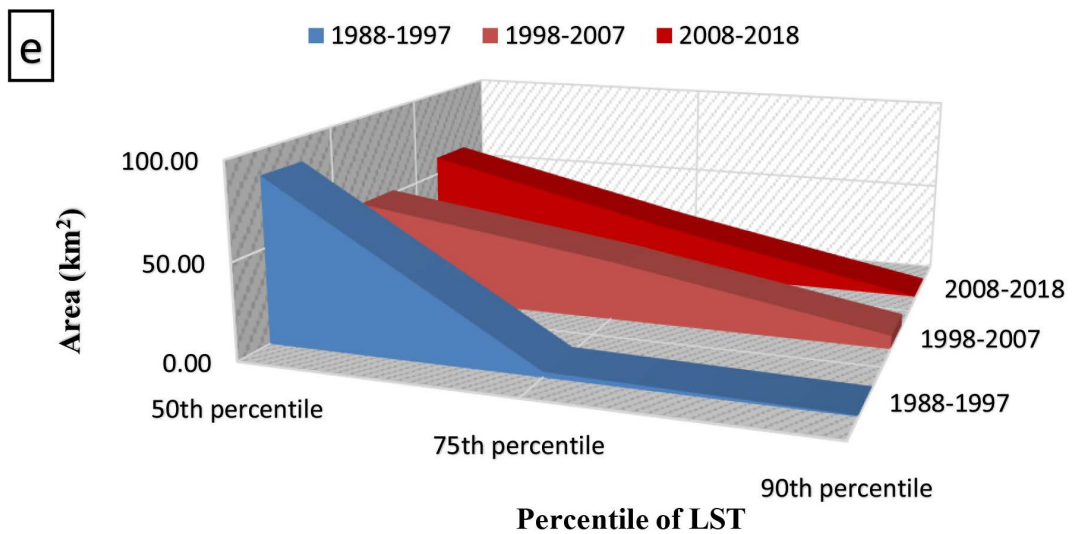

Figure 4. Urban land surface area covers by different percentile of LST groups for the corresponding month of March in the developed area (a, b, and c) and growing developing (d and e) areas.

Table 3. LULC classification and area coverage by different land covers for the corresponding month of March from 1988 to 2018 in Motijheel, Gulshan, Uttara, Demra, and Pallabi.

\begin{tabular}{|c|c|c|c|c|}
\hline \multirow{2}{*}{ Location } & \multirow{2}{*}{ Types of land coverage } & \multicolumn{3}{|c|}{ Area coverage Percentage of the total area } \\
\hline & & 1988-1997 & $1998-2007$ & 2008-2018 \\
\hline \multirow{3}{*}{ Motijheel } & Low vegetation & 12.18 & 16.37 & 2.61 \\
\hline & Medium vegetation & 48.39 & 61.35 & 68.51 \\
\hline & High vegetation & 39.43 & 22.28 & 28.88 \\
\hline \multirow{3}{*}{ Uttara } & Low vegetation & 8.26 & 3.57 & 0.18 \\
\hline & Medium vegetation & 34.80 & 59.52 & 76.22 \\
\hline & High vegetation & 56.94 & 36.91 & 23.59 \\
\hline \multirow{3}{*}{ Pallabi } & Low vegetation & 1.43 & 4.52 & 0.42 \\
\hline & Medium vegetation & 24.93 & 44.30 & 57.69 \\
\hline & High vegetation & 73.64 & 51.18 & 41.89 \\
\hline \multirow{4}{*}{ Gulshan } & Low vegetation & 3.77 & 11.24 & 2.94 \\
\hline & Medium vegetation & 21.57 & 51.01 & 57.76 \\
\hline & High vegetation & 74.66 & 37.75 & 39.30 \\
\hline & Low vegetation & 74.19 & 37.53 & 39.40 \\
\hline \multirow{3}{*}{ Demra } & Medium vegetation & 2.34 & 2.98 & 0.85 \\
\hline & High vegetation & 2.98 & 5.81 & 12.82 \\
\hline & Low vegetation & 94.68 & 91.22 & 86.33 \\
\hline
\end{tabular}

range of $75^{\text {th }}$ percentile was found that land area coverage increased by $78.45 \%$ and at the year group of $2008-2018$, the area coverage increased $98.66 \%$ by the range of $90^{\text {th }}$ percentile compared to the year group 1988 to 1997. It was also observed that, in the month of March, higher areas were also covered by that group of temperature compared to the month of April and May. It was exposed that 
during the month of April, in 2008-2018 year group, the temperature range of $50^{\text {th }}$ percentile was increased by $63.63 \%$ compared to the year group $1988-1997$ which was lower than March.

Figure 4 symbolizes the area covered with the different percentile of selected areas in the DMA. From Figure 4, it was clearly understandable that the more developed urban areas show higher percentile groups of LST values compare with growing developing areas. One of the reasons for having high temperature values for developed areas was that the bares lands were in places where there was on-going development taking place. As a result, the vegetation cover was reducing in the developed and growing developing areas Table 3 . Therefore, the background climate change was weaker than surface warming in urban areas. This implied that, in the months of March, $50^{\text {th }}$ percentile group of LST coverage areas were decreasing at the rate of $67 \%-96 \%$, the $75^{\text {th }}$ percentile group of LST coverage areas was increasing at the rate of $63 \%-74 \%$, and the $90^{\text {th }}$ percentile group of LST coverage areas was increasing at the rate of $5 \%-28.54 \%$. Similarly, in the month of May, more hotspots areas were covered by the group of $90^{\text {th }}$ percentile. On the other hand, in 2014-2018, vegetation coverage area with high NDVI ( 0.2 to1) was decreased by $13.50 \%, 35.15 \%, 25.96 \%, 6.76 \%$, and $31.70 \%$ in Motijheel, Gulshan, Uttara, Demra, and Pallabi respectively in comparison to 1988-1997, while medium range of NDVI (0.05 to 0.2 ) has been increased by $21.74 \%, 36.15 \%, 31.59 \%, 8.1 \%$ and $31.7 \%$ (Table 3). It was a well-known fact that more greenery areas led to more cooling effects. So, it was to be confirmed that vegetation coverage such as urban rooftop agriculture (URTA), gardens, forests, parks, and grasslands were well established tools for reducing urban thermal environment enhancing urban cooling through evapotranspiration and shading effect by green activities.

The study exposed that the urban LST and vegetation changes in the three periods examined in this study did not occur evenly in all directions. New developments were observed along with the urban areas as well as in the areas that had already been replaced by built up areas. The rapid change of vegetation decreases and LST increase in the more developed areas of DMA means that it was not possible for the metropolitan government to provide basic urban comforts for the population. It has led to a comprehensive range of environmental problems. In more developed areas, landfills have contributed to soil effluence, resulting in reduced vegetation and increases clumsy urbanization. The creation of landfill sites had intensified the extent of inundation in the developed area compared to growing developing areas in DMA.

\subsection{Temporal Trend of Different Percentile Groups of LST}

The yearly deviation of different percentiles of temperature was analyzed with the time series data. The monthly variation of temperature was analyzed based on the average maximum and minimum temperature of the last 30 years from 1988-2018. Figures 5(a)-(c) show the average monthly mean LST trend of DMA. 

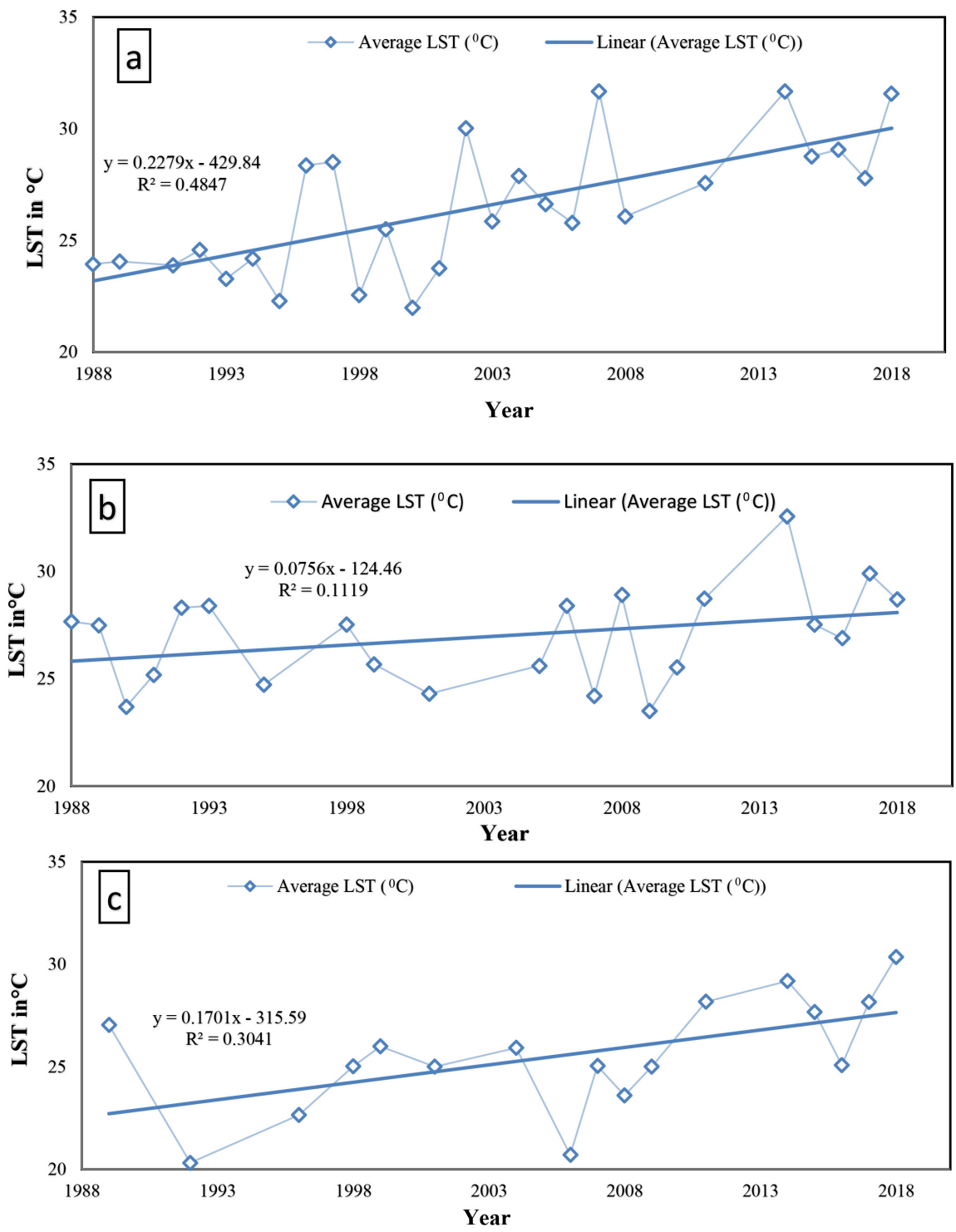

Figure 5. Temporal trend of mean LST of DMA in March (a), April (b) and May (c).

The study perceived that average high LST was found in March during the period of 1988-2018. The lowest average mean LST trend was found in the month of April. A higher monthly average temperature was observed in the month of May for the DMA.

An increase in temperature was not found significantly within the period of 1988-2018. In addition to the increase of LST induced by variations in the surface area cover condition, the general climatic warming environment represented an important background for analyzing the temporal variations. To deepen the understanding of the temporal variations, the mean value of LST data was derived from performing a near about similar trend analysis, as shown in Figure 5. The changed pattern distribution of mean LST in the month of March to May was significant, and the change trending in the month of March was more significant in comparison to the month of April and May. The mean value of LST 
had an increasing trend in urban areas. In DMA, the mean LST value was found at $24.1^{\circ} \mathrm{C}$, but due to urbanization, in the year 2018 , the mean value of LST in the same month was found at $29.8^{\circ} \mathrm{C}$. Similarly, in the month of April and May from 1988 to 2018 , the mean LST was found to increase by $4.9^{\circ} \mathrm{C}$ and $5.3^{\circ} \mathrm{C}$ in the DMA. The magnitude of the change in mean LST in the month of May was generally higher than the other month of the year.

Figures 6(a)-(f) and Figures 7(a)-(f) also show the mean LST trends both in developed (Gulshan and Motijheel) and growing developing areas (Demra and Pallabi) located around the boundary of DMA and show a strong warming effect with the higher values.

The LST value of only two Thana of growing developing areas and developed areas are presented in Figure 6 and Figure 7. Furthermore, LST of other Thana was calculated from Landsat image and analyzed and the average values of temporal trends (LST) of those selected areas were estimated. From analysis and observations of these Figure 6 and Figure 7, it was found that the mean LST of each year had an increasing trend, and the warming effect was more pronounced at the month of March $\left(\mathrm{R}^{2}=0.128\right.$ to 0.2459$)$ in higher built up areas in DMA such as Motijheel and Gulshan while the warming effect was significantly weaker
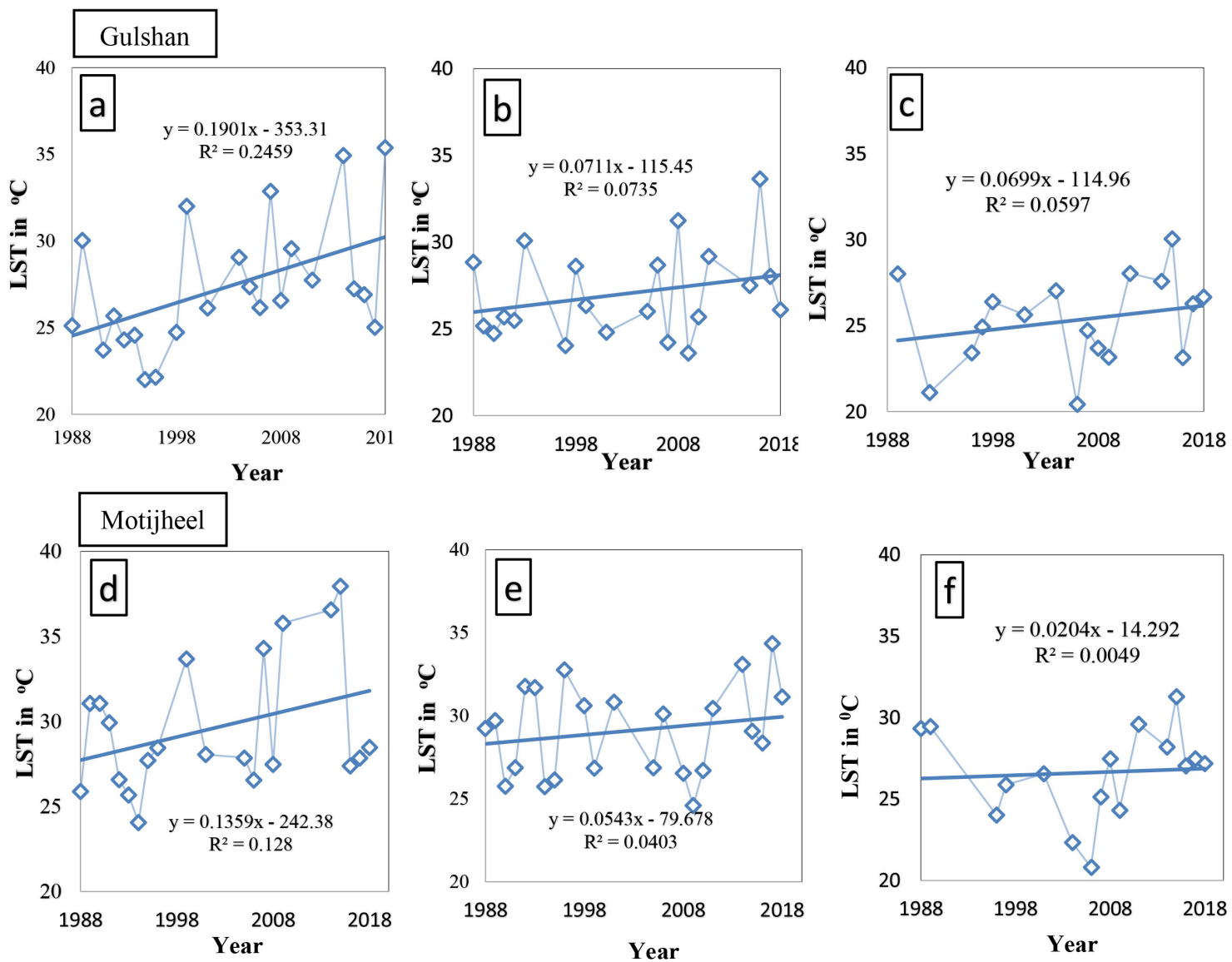

Figure 6. Temporal trend of monthly mean LST in the developed areas during March, April, and May (Gulshan-a, b, and c; Motijheel-d, e, and f). 

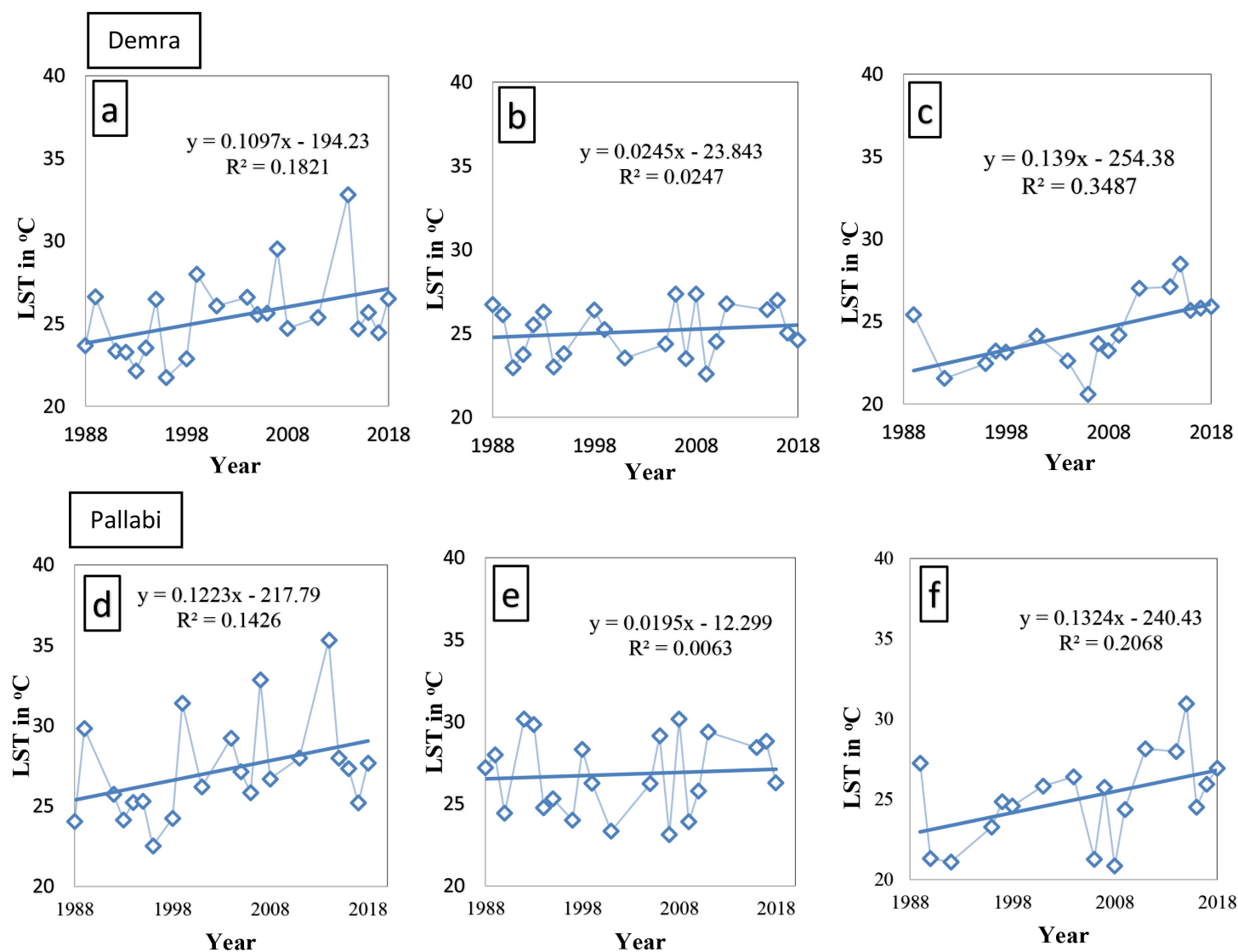

Figure 7. Temporal trend of monthly mean LST in the growing developing areas during March, April, and May (Demra-a, b, and c, Pallabi-d, e, and f).

$\left(R^{2}=0.0049\right.$ to 0.0587$)$ at the month of May. On the other hand, LST was higher at the month of May $\left(\mathrm{R}^{2}=0.2068\right.$ to 0.3487$)$ in the growing, developing areas such as Demra and Pallabi. Analysis of the trends using the average temporal values of LST of the developing and developed areas from 1988 to 2018 of those selected areas showed that the most developed and growing developing areas had a positive trend of LST in the month of March to May.

Less significant trends were found for the months of April in both areas. The average value of LST in more developed areas was increased by $6.3^{\circ} \mathrm{C}, 3.10^{\circ} \mathrm{C}$, and $5.3^{\circ} \mathrm{C}$ for the months of March, April, and May over the last 30 years. Similarly, the average value of LST in the growing developed areas was increased by $6.1^{\circ} \mathrm{C}, 3.1^{\circ} \mathrm{C}$, and $3.2^{\circ} \mathrm{C}$ for the months of March, April, and May, respectively for the last 30 years. So, a change of LST was more sensitive in the more developed areas compare to growing developing areas. Therefore, changes of different ranges of LST both in developed and growing developing areas frequently covered by built up areas, were directly related to the expansion of built-up areas. However, due to the warming effect of climate change, from the above discussion, it is clear that LST is the major issue and factor of climate change as well as global warming. This phenomenon is more reflected in the city center of urban areas, especially the more developed areas. 


\subsection{Comparison between Vegetation Coverage and Different Percentile of LST with Developed and Growing Developed Areas in DMA}

Urban growth is common in developing countries, while their growing process and patterns are different due to different urban planning, administrative policies and for their different urban landscapes. The urbanization amplitude of the foremost developed Thanas, like Motijheel, Gulshan, and Uttara, was analyzed applying the Landsat image. It was found lower as compared to the growing developed areas like Demra and Pallabi and was consistent with the urban land cover changes. The massive area of vegetation to a populated area could contribute significantly to the UHI effects of the DMA by increasing LST. The areas with high temperature also tended to possess lower NDVI values. This aspect was corroborated through the analysis of the correlation between LST and NDVI. Therefore, the correlation between NDVI and LST from the visual interpretation of NDVI and LST contrasts was crystal clear. Within the LST images, the LST values of low-vegetated areas (built-up, barren, dried riverbeds) were above those obtained for areas concerning waterbodies, vegetation, and agricultural land. Table 3 shows that the peaks of the LST were found usually in the built-up areas, while the troughs were found in the vegetation areas. The peaks of NDVI were found in vegetated areas. Thus, NDVI and LST showed a transparent negative correlation. In other words, the NDVI values were diminutive (or, even adverse) where LST was high and vice-versa. From Table 3, it was found that vegetation coverage within the developed area was decreased by $7 \%$ to $10 \%$ in comparison with the growing developed areas. The connection between LST and concrete land covers was investigated with an identical correlation. The very best LST was found in Motijheel which was above Demra by $37.932^{\circ} \mathrm{C}$. It was a contrast for early developing and densely built-up areas. In Demra, the medium vegetation range area was increased by $13.74 \%$ compared with the developed areas, like Motijheel. A vegetation coverage area was decreased by $6.74 \%$ within the growing, developing areas compare with developed areas in 1988-2019. So, the studies used the typical satellite images at two or three different dates within the same month. All available clear-sky images within several years were studied for the selected areas to avoid the cloud contamination and the less accuracy. It was obvious that the urban vegetation landscape played a vital role in reducing the UHI effect in the city centers. Urban planners to come forward to increase the urban green spaces through planning as mitigation tools to reduce urban heating in Dhaka City.

\section{Conclusions}

This study analyzed the land surface temperature and urbanization trend of the DMA and its impacts on the creation of UHI exhausting remote sensing and GIS tools. The results of this study clearly indicated a significant warming trend for the most developed or the most built-up areas that are facing increased UHI ag- 
gravating climate warming. It is certain that the warming trend would further deteriorate the urban ecosystem and modify the major hydro-ecological processes over the study area. An increased vegetation activity is capable to deter the current heated local environment from the urban areas eliminating climate change impacts. The spatial and temporal trends of vegetation and their effects on LST changes as per percentiles of $50^{\text {th }}, 75^{\text {th }}$, and $90^{\text {th }}$ led to conclusions that hot spot zones are assembled in the most developed areas where vegetation coverage is lower than the growing and developing areas. LST in the developed areas is more sensitive to climate changes than the growing, developing areas, and adaptation approaches or vegetation increases are needed to overcome LST increases in hotspot regions.

It is imperative to carry out analysis of urban heating impacts using multi-source satellite images/radar data for curbing of future UHI effect of DMA. The integrated use of ArcGIS, RS, and socio-economic data would be effective to understand the spatial and temporal dynamics of the major changes in both LST and NDVI.

These results are supposed to provide valuable information for urban planners and researchers to take up appropriate green actions like roof top agriculture to mitigate the UHI effects. It will pave the way of achieving sustainable urban cities. Furthermore, with these findings, the planners can predict the possible changes in urban growth configurations.

\section{Acknowledgements}

The authors thankfully acknowledge the support from the Ministry of Science and Technology of Bangladesh through the National Science and Technology (NST) doctoral degree grant. The authors also would like to convey sincere thanks to the authority of Bangladesh Agricultural Development Corporation (BADC) and Institute of Flood and Water Management (IWFM), Bangladesh University of Engineering and Technology (BUET). The authors are expressing sincere gratitude to Md. Abdullah Al Baki, Solutions Analyst of Environmental System Research Institute (ESRI), South Asia Bangladesh for helping with the remote sensing data.

\section{Conflicts of Interest}

The authors declare no conflicts of interest regarding the publication of this paper.

\section{References}

[1] Singh, P., Kikon, N. and Verma, P. (2017) Impact of Land Use Change and Urbanization on Urban Heat Island in Lucknow City, Central India. A Remote Sensing-Based Estimate. Sustainable Cities and Society, 32, 100-114. https://doi.org/10.1016/j.scs.2017.02.018

[2] Elmes, A., Rogan, J., Williams, C., Ratick, S., Nowak, D. and Martin, D. (2017) Effects of Urban Tree Canopy Loss on Land Surface Temperature Magnitude and Timing. ISPRS Journal of Photogrammetry and Remote Sensing, 128, 338-353. 
https://doi.org/10.1016/j.isprsjprs.2017.04.011

[3] Bonafoni, S. and Keeratikasikorn, C. (2018) Land Surface Temperature and Urban Density: Multiyear Modeling and Relationship Analysis Using Modis and Landsat Data. Remote Sensing, 10, 1471. https://doi.org/10.3390/rs10091471

[4] Liu, H., Zhan, Q., Gao, S. and Yang, C. (2019) Seasonal Variation of the Spatially Non-Stationary Association between Land Surface Temperature and Urban Landscape. Remote Sensing, 11, 1016. https://doi.org/10.3390/rs11091016

[5] Ibrahim, G.R.F. (2017) Urban Land Use Land Cover Changes and Their Effect on Land Surface Temperature: Case Study Using Dohuk City in the Kurdistan Region of Iraq. Climate, 5, 13. https://doi.org/10.3390/cli5010013

[6] Das Majumdar, D. and Biswas, A. (2016) Quantifying Land Surface Temperature Change from LISA Clusters: An Alternative Approach to Identifying Urban Land Use Transformation. Landscape and Urban Planning, 153, 51-65. https://doi.org/10.1016/j.landurbplan.2016.05.001

[7] Ranagalage, M., Murayama, Y., Dissanayake, D.M.S.L.B. and Simwanda, M. (2019) The Impacts of Landscape Changes on Annual Mean Land Surface Temperature in the Tropical Mountain City of Sri Lanka: A Case Study of Nuwara Eliya (1996-2017). Sustainability, 11, 5517. https://doi.org/10.3390/su11195517

[8] Dewan, A.M. and Corner, R.J. (2014) Impact of Land Use and Land Cover Changes on Urban Land Surface Temperature. In: Dhaka Megacity: Geospatial Perspectives on Urbanization, Environment and Health, Springer, Berlin, 219-238. https://doi.org/10.1007/978-94-007-6735-5_12

[9] Li, Z., Xie, C., Chen, D., Lu, H. and Che, S. (2020) Effects of Land Cover Patterns on Land Surface Temperatures Associated with Land Use Types along Urbanization Gradients in Shanghai, China. Polish Journal of Environmental Studies, 29, 713-725. https://doi.org/10.15244/pjoes/99974

[10] Dutta, D., Rahman, A., Paul, S.K. and Kundu, A. (2019) Changing Pattern of Urban Landscape and Its Effect on Land Surface Temperature in and around Delhi. Environmental Monitoring and Assessment, 191, 551. https://doi.org/10.1007/s10661-019-7645-3

[11] Ishtiaque, T.A., Tasin, Z.T. and Akter, K.S. (2017) Urban Heat Island Intensity Assessment through Comparative Study on Land Surface Temperature and Normalized Difference Vegetation Index: A Case Study of Chittagong, Bangladesh. International Journal of Civil, Environmental, Structural, Construction and Architectural Engineering, 11, 37.

[12] Rahman, M.M., Hassan, M.S., Bahauddin, K.M., Khondoker, A. and Bhuiyan, M.A.H. (2018) Exploring the Impact of Rural-Urban Migration on Urban Land Use and Land Cover: A Case of Dhaka City, Bangladesh. Migration and Development, 7, 222-239.

[13] Amin, A.K.M.K., Haque, M.A. and Alamgir, M. (2013) Analysis of the Wetland Degradation around the Vicinity of Dhaka City in Bangladesh. Asian Journal of Water, Environment and Pollution, 10, 19-26.

[14] Zhou, D., et al. (2019) Satellite Remote Sensing of Surface Urban Heat Islands: Progress, Challenges, and Perspectives. Remote Sensing, 11, 48.

https://doi.org/10.3390/rs11010048

[15] Carter, J.G. (2018) Urban Climate Change Adaptation: Exploring the Implications of Future Land Cover Scenarios. Cities, 77, 73-80. https://doi.org/10.1016/j.cities.2018.01.014

[16] Mai, M.M. and Rahman, M. (2011) Cultural Sustainability of Residential Adjust- 
ment Styles of Semi-Urban Abuja and Core Dhaka Neighborhoods. Journal of Sustainable Development and Environmental Protection, 1, 41-56.

[17] Al-Shoaibi, A.A.A., et al. (2018) Perceptions and Behavior Related to Noncommunicable Diseases among Slum Dwellers in a Rapidly Urbanizing City, Dhaka, Bangladesh: A Qualitative Study. Nagoya Journal of Medical Science, 80, 559-569.

[18] Uddin, M., Anwar, M., Rahman, M. and Mobin, M. (2015) An Investigation on the Pattern of Land Use Change in Dhaka City Using Remote Sensing and GIS Application. Journal of Environmental Science and Natural Resources, 7, 105-109. https://doi.org/10.3329/jesnr.v7i2.22217

[19] Rouf, M.A. and Jahan, S. (2007) Spatial and Temporal Patterns of Urbanization in Bangladesh. Urbanization in Bangladesh: Patterns, Issues and Approaches to Planning (pp. 1-24). Bangladesh Institute of Planners, Dhaka.

[20] Hossain, K.M.A. and Easa, S.M. (2012) Pollutant Dispersion Characteristics in Dhaka City, Bangladesh. Asia-Pacific Journal of Atmospheric Sciences, 48, 35-41. https://doi.org/10.1007/s13143-012-0004-8

[21] Raja, D.R. and Neema, M.N. (2013) Impact of Urban Development and Vegetation on Land Surface Temperature of Dhaka City. In: International Conference on Computational Science and Its Applications, Springer, Berlin, 351-367. https://doi.org/10.1007/978-3-642-39646-5_26

[22] Habiba, U., Zaider, F., Ishtiaque, A., Mahmud, M.S. and Masrur, A. (2011) Remote Sensing \& GIS Based Spatio-Temporal Change Analysis of Wetland in Dhaka City, Bangladesh. Journal of Water Resource and Protection, 3, 781-787. https://doi.org/10.4236/jwarp.2011.311088

[23] Raja, D.R. (2012) Spatial Analysis of Land Surface Temperature in Dhaka Metropolitan Area. Journal of Bangladesh Institute of Planners, 5, 151-167.

[24] Ahmed, B., Kamruzzaman, M., Zhu, X., Rahman, M.S. and Choi, K. (2013) Simulating Land Cover Changes and Their Impacts on Land Surface Temperature in Dhaka, Bangladesh. Remote Sensing, 5, 5969-5998.

https://doi.org/10.3390/rs5115969

[25] Julien, Y., et al. (2011) Temporal Analysis of Normalized Difference Vegetation In$\operatorname{dex}($ NDVI) and Land Surface Temperature (LST) Parameters to Detect Changes in the Iberian Land Cover between 1981 and 2001. International Journal of Remote Sensing, 32, 2057-2068. https://doi.org/10.1080/01431161003762363

[26] Islam, K., Jashimuddin, M., Nath, B. and Nath, T.K. (2018) Land Use Classification and Change Detection by Using Multi-Temporal Remotely Sensed Imagery: The Case of Chunati Wildlife Sanctuary, Bangladesh. The Egyptian Journal of Remote Sensing and Space Sciences, 21, 37-47. https://doi.org/10.1016/j.ejrs.2016.12.005

[27] Alam, M.J. and Mullick, R.A. (2014) Climate Change Effects upon Massive Land and Housing Development: Case of Dhaka, Bangladesh. International Journal of Climate Change Strategies and Management, 6, 315-331.

[28] World Bank (2016) The United Nations Population Division's World Urbanization Prospects. United Nations Popul. Div. World Urban Prospect.

[29] United Nations (2019) World Population Prospects 2019: Highlights. United Nations Publication, New York.

[30] Rahman, M.N. (2019) Urban Expansion Analysis and Land Use Changes in Rangpur City Corporation Area, Bangladesh, Using Remote Sensing (RS) and Geographic Information System (GIS) Techniques. Geosfera Indonesia, 4, 217-229. https://doi.org/10.19184/geosi.v4i3.13921

[31] Bangladesh Population Census (2001) and Bangladesh Bureau of Statistics (2019). 
[32] Cai, Q., Li, E. and Jiang, R. (2017) Analysis of the Relationship between Land Surface Temperature and Land Cover Changes Using Multi-Temporal Satellite Data. Nature Environment and Pollution Technology, 16, 1035-1042.

[33] Sussman, H.S., Raghavendra, A. and Zhou, L. (2019) Impacts of Increased Urbanization on Surface Temperature, Vegetation, and Aerosols over Bengaluru, India. Remote Sensing Applications. Society and Environment, 16, Article ID: 100261. https://doi.org/10.1016/j.rsase.2019.100261

[34] Hu, Y., Jia, G., Hou, M., Zhang, X., Zheng, F. and Liu, Y. (2015) The Cumulative Effects of Urban Expansion on Land Surface Temperatures in Metropolitan Jinjiang, China. Journal of Geophysical Research, 120, 9932-9943. https://doi.org/10.1002/2015JD023653

[35] Xie, Q, Zhou, Z., Teng, M. and Wang, P. (2012) A Multi-Temporal Landsat TM Data Analysis of the Impact of Land Use and Land Cover Changes on the Urban Heat Island Effect. Journal of Food, Agriculture and Environment, 10, 803-809.

[36] Mathew, A., Khandelwal, S. and Kaul, N. (2018) Spatio-Temporal Variations of Surface Temperatures of Ahmedabad City and Its Relationship with Vegetation and Urbanization Parameters as Indicators of Surface Temperatures. Remote Sensing Applications: Society and Environment, 11, 119-139.

https://doi.org/10.1016/j.rsase.2018.05.003

[37] Bhattacharjee, S. and Ghosh, S.K. (2015) Spatio-Temporal Change Modeling of LULC: A Semantic Kriging Approach. ISPRS Annals of the Photogrammetry, Remote Sensing and Spatial Information Sciences, 2, 177-184. https://doi.org/10.5194/isprsannals-II-4-W2-177-2015

[38] Benas, N., Chrysoulakis, N. and Cartalis, C. (2017) Trends of Urban Surface Temperature and Heat Island Characteristics in the Mediterranean. Theoretical and Applied Climatology, 130, 807-816.

[39] Aina, Y.A., Adam, E.M. and Ahmed, F. (2017) Spatiotemporal Variations in the Impacts of Urban Land Use Types on Urban Heat Island Effects: The Case of Riyadh, Saudi Arabia. International Archives of the Photogrammetry, Remote Sensing and Spatial Information Sciences, 42, 9-14. https://doi.org/10.5194/isprs-archives-XLII-3-W2-9-2017

[40] Saini, V. and Tiwari, R.K. (2017) Effect of Urbanization on Land Surface Temperature and NDVI: A Case Study of Dehradun, India, Study of Glacier Dynamics Using Advanced Remote Sensing Techniques.

[41] Yaa'Cob, N., Abd Rashid, Z.N.A., Tajudin, N. and Kassim, M. (2020) Landslide Possibilities Using Remote Sensing and Geographical Information System (GIS). IOP Conference Series. Earth and Environmental Science, 540, Article ID: 012084. https://doi.org/10.1088/1755-1315/540/1/012084

[42] Bidoglio, G., Berger, M. and Finkbeiner, M. (2019) An Environmental Assessment of Small Hydropower in India: The Real Costs of Dams' Construction under a Life Cycle Perspective. The International Journal of Life Cycle Assessment, 24, 419-440. https://doi.org/10.1007/s11367-018-1458-4

[43] Ayalew, L. and Hiromitsu, Y. (2005) The Application of GIS-Based Logistic Regression for Landslide Susceptibility Mapping in the Kakuda-Yahiko Mountains, Central Japan. Geomorphology, 65, 15-31. https://doi.org/10.1016/j.geomorph.2004.06.010

[44] Barreca, F. (2016) Rooftop Gardening. A Solution for Energy Saving and Landscape Enhancement in Mediterranean Urban Areas. Procedia Social and Behavioral Sciences, 223, 720-725. https://doi.org/10.1016/j.sbspro.2016.05.248 